\title{
Sleep during COVID-19 lockdown: a cross-cultural pilot
}

\section{study}

Cristina Florea*1, Pavlos Topalidis ${ }^{* 1}$, Theresa Hauser ${ }^{1}$, Monika Angerer ${ }^{1}$, Anton

Kurapov$^{2}$, Carlos Alberto Beltran Leon ${ }^{3} \&$ Manuel Schabus ${ }^{1}$

${ }^{1}$ Laboratory for Sleep, Cognition \& Consciousness Research, Centre for Cognitive Neuroscience Salzburg (CCNS), Paris-Lodron University of Salzburg, Austria

2 Department of Experimental and Applied Psychology, Faculty of Psychology, Taras

Shevchenko National University of Kiev, Ukraine

${ }^{3}$ Institute of Neurology and Neurosurgery, Department of Clinical Neurophysiology, Havana,

Cuba

Corresponding Author:

Manuel Schabus,

Hellbrunnerstr. 34

A- 5020 Salzburg, Austria

manuel.schabus@sbg.ac.at

Tel.: $+436628044-5113$

Conflicts of interest:

All authors declare no competing interests.

Author contributorship:

Conceptualisation of the study: MS, MA, CF, PT

Data collection and data proofing $\mathrm{CF}, \mathrm{PT}, \mathrm{TH}, \mathrm{AK}, \mathrm{MS}, \mathrm{CABL}$

Data analysis: CF, PT, MS

Manuscript writing: CF, MS, PT

Manuscript review: MS 


\section{Summary}

2 Our study aimed to assess the change in the sleep patterns during the Coronavirus

3 lockdown in five regions (Austria/Germany, Ukraine, Greece, Cuba and Brazil), using

4 online surveys, translated in each language. Part of the cohort was collected directly

5 during lockdown, to which retrospective cross-sectional data from and after lockdown

6 (retrospective) questionnaires ware added. We investigated sleep times and sleep

7 quality changes from before to during lockdown and found that, during lockdown,

8 participants had (i) worse perceived sleep quality for those who reported to be worried

9 by COVID-19, (ii) a shift of bedtimes to later hours during workdays, and (iii) a sleep

10 loss on free days (resulting from more overall sleep during workdays), leading to (iv) a

11 marked reduction of social jetlag across all cultures.

12 For further analyses we then split the participants by job (system relevant or not)

13 because it was assumed that the nature of the lockdown's consequences is dependent

14 upon system relevance. System relevant jobs were found to have earlier wake-up

15 times as well as shorter total sleep times on workdays, leading to a higher social jetlag

16 for people in system relevant jobs.

17 Cultural differences revealed a general effect that participants from Greece and

18 Ukraine had later bedtimes (on both work and free days) and wake-up times (on

19 workdays) than Cuba, Brazil and Austria, irrespective of COVID-19 lockdown

20 restrictions.

21

22 Keywords:

23 COVID-19, pandemic, sleep habits, sleep problems, cross-cultural, social jetlag 24 
26 cultural pilot study

\section{Introduction}

\section{Sleep during COVID-19 lockdown: a cross-}

In December 2019 a cluster of pneumonia cases developed in the Wuhan province of China, generated by the subsequently identified SARS-CoV2 (severe acute respiratory syndrome - coronavirus 2$)^{1}$. The high contagiosity of the virus drove to a rapid worldwide spread of the coronavirus-disease (COVID-19), leading to the declaration of a pandemic by the World Health Organization (WHO) on 11th of March $2020^{2}$. This prompted countries to impose strict social distancing measures, including the recommendation to stay at home, the ban on group meetings, and the shutdown of schools and non-essential commercial activities ${ }^{3}$. The effects of 'grounding' a nation reduced the spread of the virus ${ }^{4}$, but also forced people to drastically change their social behaviour and everyday habits, such as fixed waking up and going to work times, having regular mealtimes, having scheduled sports and leisure activities, as well as social events. These timekeepers, which kept one's habitual activity/rest rhythm, were suddenly disturbed due to the lockdown measures, leading to changes in one's circadian rhythm ${ }^{5}$. For example, the social pressure to wake up early during workdays was partially removed during the lockdown for people who could work from home and/or on a more flexible time schedule. This was found to reduce the difference between sleep times on workdays and sleep times on free days, commonly referred as social jetlag ${ }^{6}$. In addition, the concern about the disease itself, the worry about personal health and about one's family's health, as well as the anxiety about the future of one's workplace and financial situation had a strong impact upon the psychological state of the general population. Numerous reports show a decline in mental health, quality of 
49 life and quality of sleep in populations affected by the pandemic ${ }^{6-16}$, with healthcare

50 workers under the most pressure ${ }^{17,18}$.

51 The current study aims to investigate how sleep patterns and sleep quality changed

52 during the lockdown, and if this varies from one country to another. First, we

53 hypothesized that sleep quality negatively correlates to the amount of worrying about

54 the ongoing pandemic. Furthermore, based on the study by Blume et al. ${ }^{6}$, we

hypothesized that, during lockdown, there will be a shift of sleep times to later hours during workdays and consequently an attenuation of the social jetlag, as well as lower sleep quality ${ }^{6-16}$ given the collateral damage of the lockdown measures.

Importantly, we hypothesized that participants having system relevant jobs (workers in health care and public service, as well as IT workers maintaining the IT systems in offices and institutions) may display different effects, with such jobs showing earlier wake-up times, less overall sleep and less reduction of social jetlag.

We also distributed our survey in various countries including Austria, Cuba, Germany,

63 Greece, Ukraine and Brazil to examine whether cultural effects may alter the observed 64 changes in sleep during the pandemic.

\section{Methods}

66 Data collection: Data was collected in two phases: (i) during and (ii) after lockdown.

67 During lockdown, a cohort was gathered through a set of two questionnaires: an entry 68 questionnaire and a morning protocol. The entry questionnaire was a one-time survey containing questions about demographics and habitual sleep times before the COVID19 situation, as well as about the quality of sleep, and the changes in work patterns and environment. The morning protocol was a survey that had to be completed daily, for about seven days, containing questions about the previous night's sleep and about 
the amount of worry for the ongoing COVID-19 pandemic. An average of 4.94 workdays and 3.46 free days were collected from each participant.

Since the acquired cohort was too small when the lockdowns were lifted for the first time, a second roll-out of the survey followed immediately after lockdown. This was a one-time survey where we pooled the questions of the two above-mentioned questionnaires, asking about sleep habits before and sleep habits during lockdown, on workdays and on free days separately. These cross-sectional data were then added, and averages for each sleep value were computed.

Considering the novelty of the COVID-19 situation, standardized sleep questionnaires did not appear sufficient and were extended by questions concerning working from home, being worried about the epidemic, or changes in sleep behaviour during as compared to before lockdown. All questions were reviewed and approved by the Ethics Committee of the University of Salzburg.

All questionnaires were generated in LimeSurvey and had versions in 6 languages:

German, English, Greek, Ukrainian, Spanish and Portuguese. The link to the questionnaires was distributed through social media platforms (e.g., Facebook, Twitter) and with the help of collaboration partners from other universities. The data from the first set of questionnaires (the cohort) was acquired for each country depending on the lockdown dates: Austria: 15.03.2020 - 29.05.2020, Germany: 22.03.2020 - 11.05.2020, Ukraine: 12.03.2020 - 02.06.2020, Greece: 12.03.2020 - 11.05.2020, and Cuba: 20.03.2020 - 10.07.2020. Data from Brazil were only collected in the second phase in a cross-sectional, one-time retrospective questionnaire. The start dates were set to the start of nationwide restrictions of mobility and to schools and shops closing, and the end dates correspond to the reopening of schools and shops (and mostly return of the workers to their normal offices). The cross-sectional data, collected with the single questionnaire, were acquired from 23.06.2020 until 16.09.2020 and the questions referred specifically to sleep habits "before lockdown" and "during lockdown". For most 
100

101

102

103

104

105

106

107

108

109

110

111

112

113

114

115

116

117

118

119

120

121

122

123

124

125

126

countries (except for Cuba, where the lockdown was still in place until 30.09.2020), this data was retrospective. We are aware that the survey answers might be influenced by a response bias ${ }^{19}$, as we had no other objective measures of sleep in the current study, however, we tried to sample data during or as close as possible to the lockdowns.

Since this was an ad hoc study, triggered by the COVID-19 pandemic and the sudden social distancing restrictions, the choice of these five countries was also motivated by pre-existing collaborations that would speed up data collection in this novel situation.

Participants: Inclusion criteria for the participants were: age 25-65 and living in one of the countries mentioned above. In total, 381 participants fulfilled these criteria. After a preliminary analysis, we found that 11 participants working in the food industry had a very different pattern of sleep/wake hours compared to the other job categories. As the group was too small to be considered separately, we had to exclude them, which left us with 370 participants, from which 71 were living in Austria and Germany, 62 in Greece, 78 in Ukraine, 95 in Cuba and 64 in Brazil. Out of the 370 participants, 12.7\% (47) were from the cohort data and the rest of $87.3 \%$ (323) were from the cross-sectional, retrospective data. For analysis of each sleep variable, we excluded outliers (3 standard deviations from the group mean) and missing values.

We defined system relevant jobs as activity in areas that could not be shut down but and rather expected increases in the amount of work during lockdown. Because of the expected strain on the healthcare system, health care professionals were included. In addition, we included public service employees such as postal office workers, bus drivers, or workers in administration, as well as people working in IT, because of the increased workload for those managing the IT systems for institutions and companies that moved their activity online. In total, 108 participants had system relevant jobs (health care, public service, IT) and 262 system irrelevant jobs (any other job, retired or unemployed, domestic occupation or no answer). People in system-relevant jobs were 
127 less susceptible to be sent on home office, forced holiday or unpaid leave of absence

128 (Supp. Fig. 1 - How the COVID-19 lockdown affected job routines for participants in 129 different job groups). The mean age was 39.2 years $(S D=11.2)$ (see Suppl. Table 1 130 for an overview of sociodemographic data).

Measurement: For each participant, the data was collected separately for workdays and free days. Sleep values collected included bedtime, wake-up-time and subjective total-sleep-time. From data we derived time-in-bed and social jetlag, with time-in-bed, a more objective measure of sleep duration (and validation of the subjective total-sleeptime), calculated as the simple difference between wake-up-time and bedtime (e.g. $07: 15_{(02 \mathrm{Apr})}$ to $\left.23: 45_{(01 \mathrm{Apr})}=07: 30\right)$. Social jetlag was computed as mid-sleep point (rree days) - mid-sleep point $_{\text {(workdays). }}$ The mid-sleep point was thereby calculated as bedtime + (wake-up-time - bedtime) $) / 2\left(\right.$ e.g. $23: 45_{(01 \mathrm{Apr})}+\left(07: 15_{(02 \mathrm{Apr})}-23: 45_{(01 \mathrm{Apr})}\right) / 2=23: 45_{(01 \mathrm{Apr})}$ $\left.+07: 30 / 2=23: 45_{(01 \mathrm{Apr})}+03: 45=03: 30_{(02 \mathrm{Apr})}\right)$.

142 Data processing: Data analysis was performed in Matlab version $2019 b^{20}$. Averages 143 for each sleep value described above were computed for each country and for each 144 job. The total number of participants was too low to be able to divide them further by 145 job within each country, so in this pilot study we only ran statistical analyses on job 146 groups and on countries separately.

148 Statistical Analysis: Statistical analysis was performed in R, version 3.6 ${ }^{21}$. Due to a 149 significant country effect on age $\left(F(4,365)=5.88, p<.001, \eta^{2}=0.06\right)$, as well as job 150 effect on age $\left(F(1,368)=14.52, \mathrm{p}<.001, \eta^{2}=0.04\right)$, main effects and interactions were analysed while controlling for age. Thus, a two way mixed ANCOVA with withinsubjects factor "COVID-19" (before vs. after), between-subjects factor "country"

153 (Greece vs. Ukraine vs. Cuba vs. Austria vs. Brazil) and "age" as a covariate was 
154

155

156

157

158

159

160

161

162

163

164

165

166

167

168

169

170

171

172

173

174

175

176

177

178

performed to examine country and COVID-19 lockdown effects separately for free and workdays, while controlling for age. Similarly, a two way mixed ANCOVA with withinsubjects factor "COVID-19" (before vs. during), between-subjects factor "job" (system relevant vs. system irrelevant), and "age" as covariate, was performed in order to explore job x COVID-19 effects, separately for free and workdays. Post-hoc analysis of significant main effects was performed using Bonferroni-corrected pairwise marginal mean comparisons, using the "rstatix" package ${ }^{22}$. Similar analysis was used on social jetlag scores. The "age x COVID-19" interaction on social jetlag scores was explored by statistically comparing Fisher-transformed correlation coefficients using a paired ttest. The effects of COVID-19-related worry on sleep quality was examined using both a chi-square and Spearman's correlation. Note that for the chi-square analysis the "I don't worry at all" and "I barely worry" responses were merged to achieve a comparable number of observations.

\section{Results}

\section{Effects of COVID-19 pandemic on sleep time variables}

\section{Total-sleep-time}

Analysis of total-sleep-time on free days, revealed a significant COVID-19 effect $(F(1$, $317)=5.155, p=.024, \eta^{2}=.016$ ), suggesting that participants slept more before (mean $(M)=08: 23, S D=01: 07)$ than during COVID-19 lockdown on free days $(M=08: 13, S D$ $=01: 13$ ) as they seemed to make up for their sleep already during workdays (cf. Table $\left.1 ; M_{\text {before }}=07: 19, S D=01: 07 ; M_{\text {during }}=07: 30, S D=01: 11\right)$. Latter effect however, was not significant across all subjects $\left(F(1,317)=.006, p=.941, \eta^{2}<0.01\right)$. In addition, there was a general and significant country effect on both free $(F(4,314)=$ $\left.3.72, p=.006, \eta^{2}<0.045\right)$ and workdays $\left(F(4,314)=5.01, p<.001, \eta^{2}<0.06\right)$. On free days, Cuba $(M=08: 33, S D=01: 01)$ slept significantly more than Greece $(M=08: 03$, 
$179 S D=01: 10)$, Ukraine $(M=08: 24, S D=01: 18)$, Austria $(M=08: 09, S D=00: 59)$ and

180 Brazil $(M=08: 09, S D=01: 16)$, and on workdays, Cuba $(M=07: 34, S D=01: 03)$ and

181 Ukraine $(M=07: 43, S D=01: 12)$ slept significantly more than Greece $(M=07: 11, S D=$

$18201: 08)$, Austria $(M=07: 04, S D=01: 01)$ and Brazil $(M=07: 14, S D=01: 14)$.

183 In addition, there was a significant effect of job on workdays $(F(1,317)=6.74, p=.01$,

$\left.184 \eta^{2}=.021\right)$ revealing that participants with system relevant jobs slept significantly less

$185(M=07: 09, S D=01: 04)$ than participants with system irrelevant jobs $(M=07: 31, S D=$

$18601: 10)$. This was not the case on free days $\left(F(1,317)=0.269, p=.604, \eta^{2}<0.01\right.$; cf.

187 Figure 1A).
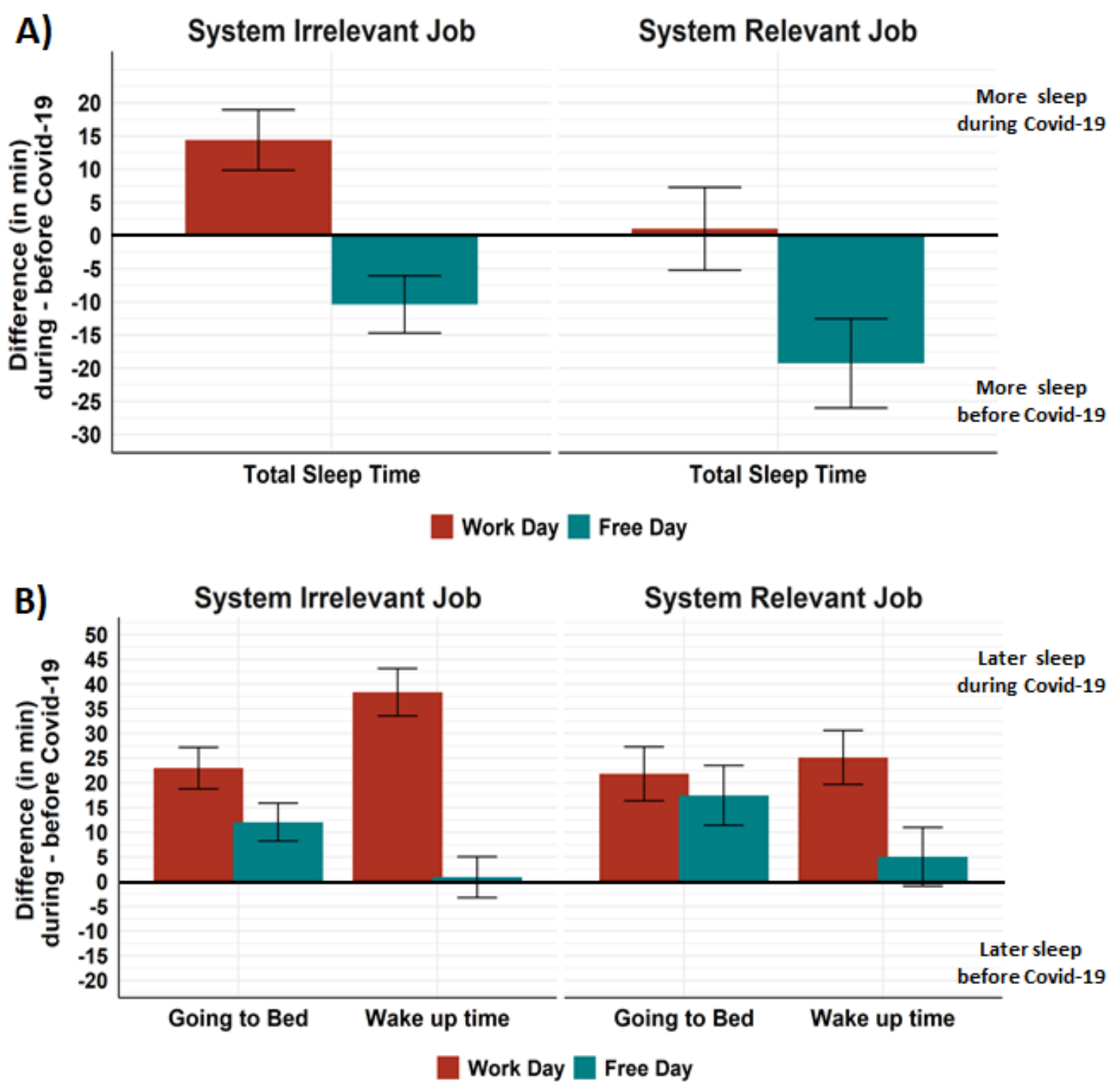
Figure 1: (A) Differences in total-sleep-times during minus before COVID-19 lockdown,

190 for system relevant and system irrelevant jobs. On workdays (red) participants with 191 system irrelevant jobs sleep more during lockdown than before, but participants with 192 system relevant jobs do not. On free days (green), all participants sleep less during the 193 lockdown than before. (B) Differences in bedtimes and wake up times during minus before COVID-19 lockdown, for system relevant and system irrelevant jobs. On workdays (red), both job groups go to bed and wake up later during lockdown than before. On free days (green), participants from both job groups go to bed a little later during than before the lockdown, but wake up at almost the same time as before the lockdown. Negative values describe a loss of sleep during lockdown; positive values describe a gain in sleep during lockdown.

\section{Time-in-bed}

201 Time-in-bed data confirms these results. For detailed results, see Supp. Table 2.

\section{Bedtimes}

203

204

205

206

207

208

209

210

211

212

213

214

Analysis of bedtimes revealed a significant COVID-19 effect on workdays $(F(1,318=$ 17.019, $\left.p<.001, \eta^{2}=.051\right)$, with earlier bedtimes before COVID-19 lockdown $(M=$ 23:21, $S D=01: 06)$ than during lockdown $(M=23: 44, S D=01: 23)$, but this was not the case for free days $\left(F(1,318)=2.081, p=.15, \eta^{2}=.007\right)$.

Furthermore, there was a significant country effect for both work $(F(4,315)=11.25, p$ $\left.<.001, \eta^{2}=.125\right)$ and free days $\left(F(4,315)=10.10, p<.001, \eta^{2}=.114\right)$. On free days Greece had later bedtimes $(M=01: 06, S D=01: 17)$ than every other country: Brazil $(M$ $=00: 12, S D=01: 37)$, Cuba $(M=00: 01, S D=01: 10)$, Austria $(M=23: 58, S D=01: 09)$, Ukraine $(M=00: 09, S D=01: 17)$. On workdays, Ukraine $(M=23: 43, S D=01: 20)$ had significantly later bedtimes than Austria $(M=23: 16, S D=00: 55)$ and Cuba $(M=23: 06$, $S D=00: 55)$ but not Brazil $(M=23: 00, S D=01: 28)$, while Greece had later bedtimes $(M=00: 17, S D=01: 17)$ than every other country. 
215 The effect of job as well as the job x COVID-19 interactions did not reach statistical 216 significance.

217

\section{Wake-up-time}

219 Analysis of the wake-up-times on workdays revealed a significant COVID-19 effect $220\left(F(1,312)=26.75, p<.001, \eta^{2}=.079\right)$ with later wake-up-times during COVID-19 221 lockdown $(M=07: 23, S D=01: 30)$ as compared to before lockdown $(M=06: 48, S D=$ 222 1:09). But this was not the case for free days $\left(F(4,312)=2.284, p=.132, \eta^{2}=.004\right)$. 223 In addition, there was a country effect for both free $\left(F(4,312)=4.723, p=.001, \eta^{2}=\right.$ $224.057)$ and workdays $\left(F(4,312)=7.902, p<.001, \eta^{2}=.092\right)$. On free days, Greece $(M=$ $22509: 08, S D=01: 39)$ had later wake-up-times than Brazil $(M=08: 27, S D=01: 41)$, 226 Austria $(M=08: 25, S D=01: 41)$ and Ukraine $(M=08: 44, S D=01: 38)$, but not Cuba $(M$ $227=0: 35, S D=01: 09)$. On workdays, Greece $(M=07: 27, S D=01: 31)$ and Ukraine $(M=$ 228 $07: 39, S D=01: 28)$ had later wake-up-times than Cuba $(M=06: 42, S D=00: 58)$, Austria $(M=06: 47, S D=01: 04)$, and Brazil $(M=06: 55, S D=01: 31)$ - see Table 1 for raw sleep values per country.

A. Sleep before and during lockdown on workdays

\begin{tabular}{|l|l|c|c|c|c|c|c|c|c|}
\hline \multicolumn{2}{|l|}{} & \multicolumn{2}{|c|}{ Total Sleep } & \multicolumn{2}{c|}{ Time in Bed } & \multicolumn{2}{c|}{ Going to Bed } & \multicolumn{2}{c|}{ Wake Up } \\
\hline & Mean & SD & Mean & SD & Mean & SD & Mean & SD \\
\hline \multicolumn{2}{|c|}{ Country } & & & & & & & & \\
\hline Austria * & Before & $07: 03$ & $00: 59$ & $07: 32$ & $01: 08$ & $23: 02$ & $00: 55$ & $06: 30$ & $00: 55$ \\
\hline & During & $07: 05$ & $01: 04$ & $07: 40$ & $01: 08$ & $23: 29$ & $00: 52$ & $07: 04$ & $01: 09$ \\
\hline Greece & Before & $07: 01$ & $01: 07$ & $07: 06$ & $01: 01$ & $24: 01$ & $01: 03$ & $07: 01$ & $01: 12$ \\
\hline
\end{tabular}




\begin{tabular}{|c|c|c|c|c|c|c|c|c|c|}
\hline & During & 07:20 & 01:08 & $07: 25$ & $01: 11$ & 24:32 & 01:28 & 07:53 & $01: 41$ \\
\hline \multirow[t]{2}{*}{ Ukraine } & Before & 07:33 & 01:08 & 07:50 & $00: 58$ & 23:35 & 01:10 & $07: 23$ & $01: 20$ \\
\hline & During & $07: 52$ & 01:15 & 08:06 & $01: 17$ & $23: 51$ & 01:29 & $07: 54$ & 01:33 \\
\hline \multirow[t]{2}{*}{ Cuba } & Before & 07:33 & 01:03 & 07:36 & $00: 56$ & $22: 56$ & $00: 50$ & 06:30 & $00: 48$ \\
\hline & During & $07: 34$ & 01:04 & $07: 43$ & 01:02 & $23: 15$ & $00: 59$ & $06: 54$ & 01:04 \\
\hline \multirow[t]{2}{*}{ Brazil } & Before & 07:08 & 01:09 & $07: 21$ & $00: 57$ & 23:17 & 01:12 & 06:35 & $01: 10$ \\
\hline & During & $07: 21$ & 01:18 & 07:33 & $01: 17$ & $23: 43$ & 01:41 & $07: 15$ & $01: 45$ \\
\hline \multicolumn{2}{|c|}{ Job } & & & & & & & & \\
\hline \multirow{2}{*}{$\begin{array}{l}\text { System } \\
\text { Relevant }\end{array}$} & Before & 07:09 & 01:02 & $07: 16$ & $00: 58$ & 23:09 & $00: 56$ & $06: 27$ & $00: 52$ \\
\hline & During & 07:10 & 01:07 & 07:20 & 01:05 & 23:32 & 01:10 & $06: 53$ & $01: 18$ \\
\hline \multirow{2}{*}{$\begin{array}{l}\text { System } \\
\text { Irrelevant }\end{array}$} & Before & 07:23 & 01:08 & $07: 36$ & 01:01 & 23:26 & 01:09 & $06: 57$ & $01: 13$ \\
\hline & During & $07: 38$ & 01:11 & 07:52 & $01: 13$ & $23: 49$ & 01:28 & $07: 36$ & 01:32 \\
\hline
\end{tabular}

B.Sleep before and during lockdown on free days

\begin{tabular}{|c|c|c|c|c|c|c|c|c|c|}
\hline & & Tota & leep & Time & Bed & Going & Bed & Wa & Up \\
\hline & & Mean & SD & Mean & SD & Mean & SD & Mean & SD \\
\hline & & & & & & & & & \\
\hline Austria * & Before & 08:21 & $00: 55$ & 08:41 & $00: 57$ & $23: 55$ & 01:11 & 08:31 & 01:17 \\
\hline
\end{tabular}




\begin{tabular}{|c|c|c|c|c|c|c|c|c|c|}
\hline & During & 07:58 & 01:02 & 08:29 & 01:01 & 24:00 & 01:08 & $08: 19$ & $01: 18$ \\
\hline \multirow[t]{2}{*}{ Greece } & Before & 08:07 & 01:02 & 08:07 & $00: 58$ & $24: 59$ & 01:16 & 09:04 & $01: 38$ \\
\hline & During & $07: 59$ & $01: 18$ & 08:01 & 01:15 & $25: 12$ & 01:29 & $09: 12$ & $01: 42$ \\
\hline \multirow[t]{2}{*}{ Ukraine } & Before & $08: 27$ & $01: 18$ & 08:38 & 01:05 & 24:03 & 01:08 & $08: 42$ & $01: 34$ \\
\hline & During & 08:20 & $01: 20$ & 08:30 & 01:12 & $24: 15$ & $01: 25$ & $08: 46$ & $01: 42$ \\
\hline \multirow[t]{2}{*}{ Cuba } & Before & 08:38 & 01:00 & 08:41 & $00: 59$ & $23: 58$ & 01:14 & 08:37 & 01:08 \\
\hline & During & 08:29 & 01:02 & 08:34 & 01:01 & 24:03 & 01:05 & $08: 32$ & 01:09 \\
\hline \multirow[t]{2}{*}{ Brazil } & Before & 08:15 & $01: 12$ & 08:28 & $00: 55$ & 24:02 & 01:17 & 08:22 & $01: 26$ \\
\hline & During & 08:04 & $01: 21$ & $08: 14$ & 01:19 & $24: 22$ & $00: 15$ & 08:31 & $01: 55$ \\
\hline \multicolumn{10}{|l|}{ Job } \\
\hline \multirow{2}{*}{$\begin{array}{l}\text { System } \\
\text { Relevant }\end{array}$} & Before & $08: 27$ & $00: 58$ & 08:28 & 01:03 & $23: 59$ & 01:10 & $08: 30$ & 01:09 \\
\hline & During & 08:10 & 01:09 & 08:20 & 01:07 & $24: 16$ & 01:22 & $08: 34$ & $01: 25$ \\
\hline \multirow{2}{*}{$\begin{array}{l}\text { System } \\
\text { Irrelevant }\end{array}$} & Before & $08: 22$ & $01: 10$ & 08:33 & $00: 59$ & $24: 15$ & 01:19 & $08: 43$ & $01: 47$ \\
\hline & During & $08: 15$ & $01: 15$ & $08: 24$ & 01:12 & $24: 23$ & 01:30 & $08: 43$ & $01: 51$ \\
\hline
\end{tabular}

232 Table 1. Sleep values before and during lockdown, on workdays (A) and on free days

233 (B). All values are in $\mathrm{HH}: \mathrm{MM}$ format and represent the average from all participants in

234 that group (job or country). ${ }^{*}$ Includes values from Austria (55 participants) and

235 Germany (16 participants).

236

237 Analysis of wake-up-times showed also a significant difference between system

238 relevant and system irrelevant jobs on workdays $\left(F(1,315)=27.32, p<.001, \eta^{2}=\right.$ 
$.037)$, with participants in system relevant jobs waking up earlier $(M=06: 40, S D=$

$24001: 08)$ as compared to participants in system irrelevant jobs $(M=07: 17, S D=01: 25)$.

241 However, this was not the case for free days $\left(F(1,315)=0.007, p=.933, \eta^{2}<.001\right.$; cf.

242 Figure 1B).

243

\section{Effects of COVID-19 pandemic on social jetlag}

245 Analysis of social jetlag revealed a robust COVID-19 effect $(F(1,325)=22.24, p=$ $\left.246<.001, \eta^{2}=.064\right)$ with higher social jetlag scores before COVID-19 lockdown $(M=$

$24701: 20, S D=00: 59)$ than during lockdown $(M=00: 57, S D=00: 56)$. In addition, there

248 was a significant job effect $\left(F(1,325)=10.294, p<.001, \eta^{2}=.031\right)$ with participants in

249 system relevant jobs showing higher social jetlag scores $(M=01: 20, S D=00: 52)$

250 compared to participants in system irrelevant jobs $(M=01: 04, S D=01: 01)$ - see Figure

2512.

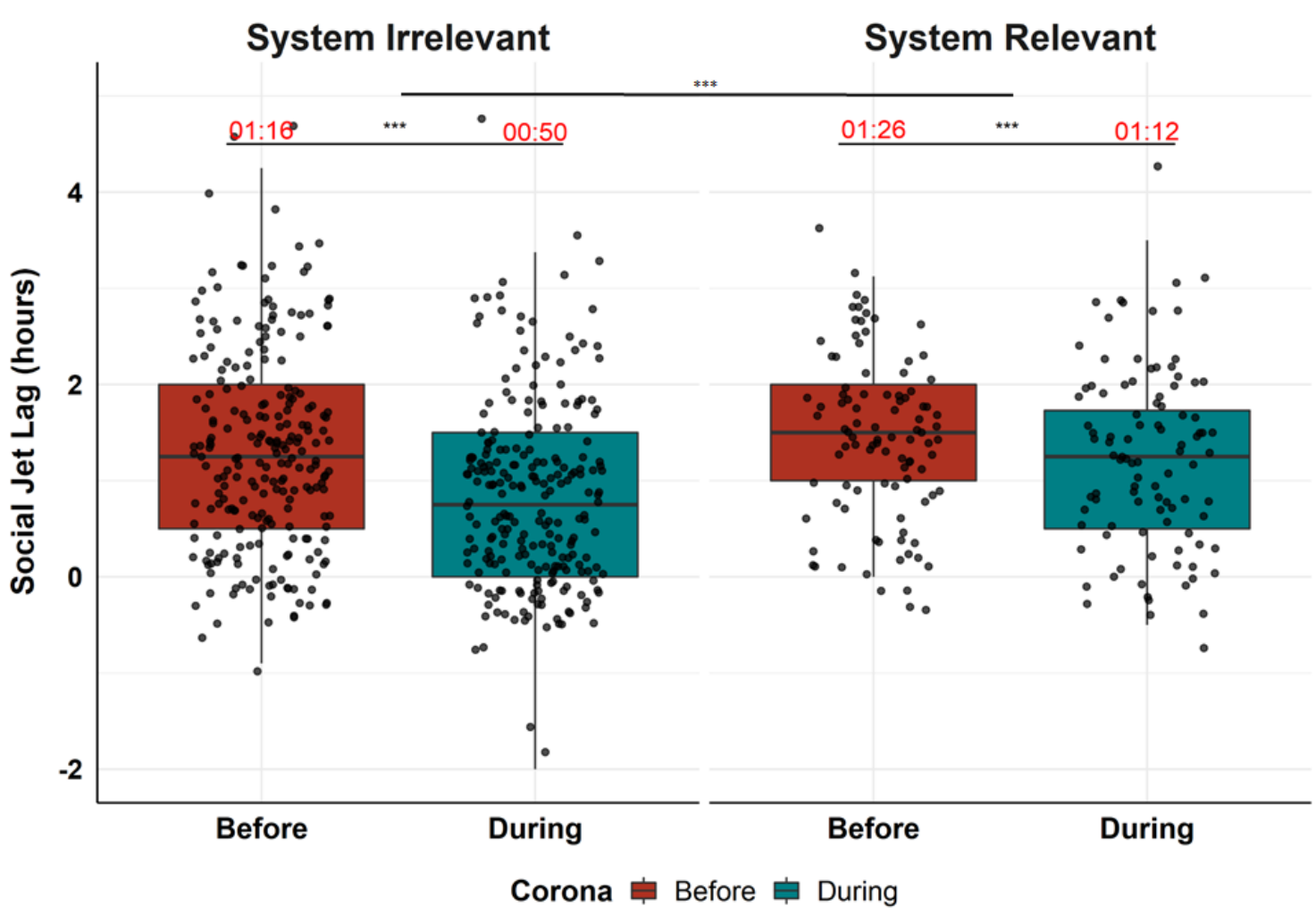


253 Figure 2: Social Jetlag in hours (difference of sleep midpoint of working minus sleep

254 midpoint of free days) for system relevant $(n=108)$ and system irrelevant $(n=262)$ jobs

255 before and during COVID-19. Note that during COVID-19 there is reduced social jetlag 256 for both groups. Participants with system relevant jobs reported higher social jetlag than 257 participants with system irrelevant jobs, independent of the COVID-19 situation. ( ${ }^{*} \mathrm{p}<$ 258 $\left..05,{ }^{* *} p<.01,{ }^{* * *} p<.001\right)$.

259

In addition, there was a significant age $\times$ COVID-19 interaction $(F(1,325)=9.46, p=$ $\left..002, \eta^{2}=.028\right)$ indicating less social jetlag with increasing age $\left(r_{s}=-0.21, p<.001\right)$, but 262 no such relation during COVID-19 lockdown $\left(r_{s}=-0.01, p=.72\right)$ (cf. Supp. Figure 2). For more details, see Supplemental Table 2.

\section{Effects of worrying about the COVID-19 pandemic on subjective}

\section{sleep quality}

267 The majority of the participants $(53 \%, N=174)$ reported that they were somewhat worried, while $22 \%(N=71)$ barely worried and $25 \%(N=81)$ worried a lot. Sleep quality did not change during lockdown for most $65 \%$ of the participants $(N=207)$, while $26 \%(N=84)$ reported a deterioration and only $12 \%(N=35)$ an improvement.

271 Analysis of the relationship between sleep quality and worry about COVID-19 pandemic revealed a significant association $\left(x^{2}(4)=20, p<.001\right)$, indicating that participants who do not (or barely) worry are less likely to sleep worse, whereas

274 participants who worry a lot about the pandemic are overrepresented in the group,

275 indicating that they are much more likely to sleep worse during lockdown (cf. Figure 3).

276 Follow-up correlational analysis between sleep quality change and worry about COVID-

27719 showed that sleep quality change and worry about COVID-19 were negatively 
278 correlated $\left(r_{s}=-0.19, p<.001\right)$. This negative correlation indicates that sleep quality 279 worsens as worry about COVID-19 increases.

280

281 For an extensive report on the results, please see Suppl. Table 2.

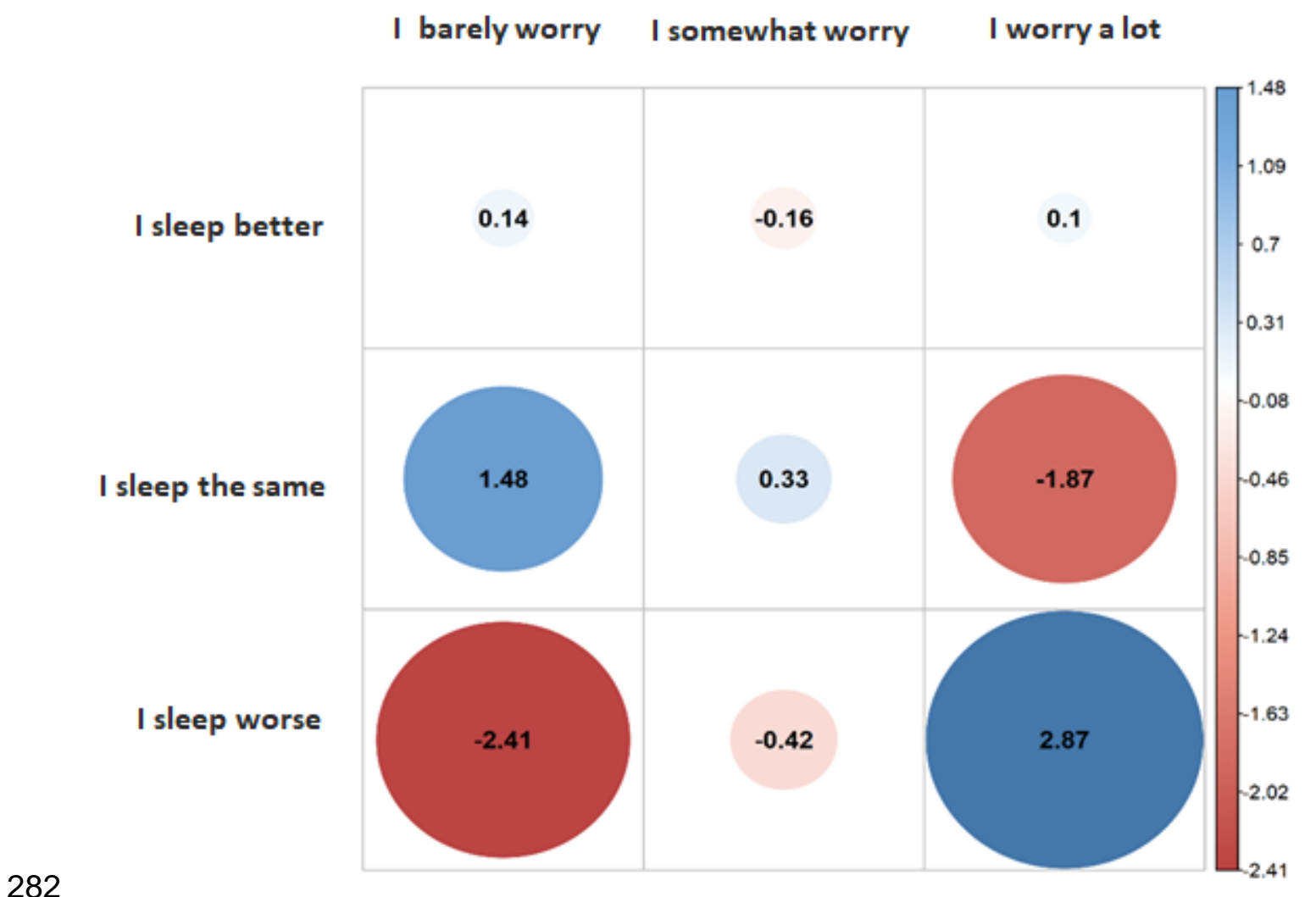

282

Figure 3: Effects of worry about the COVID-19 pandemic on subjective sleep quality

284 visualised as $x^{2}$ residuals. Note that people who do not (or barely) worry are less likely

285 (than expected) to sleep worse (in red), whereas the participants who worry a lot about

286 the pandemic are much more likely to sleep worse (in blue).

287

288 Discussion

\section{COVID-19 lockdown effects}

290 Results reveal that the lockdown had strong effects on all of the measured sleep variables. 
291 On workdays, participants started to go to bed and wake up later during lockdown than 292 before (by an average of 23 minutes and, respectively, 35 minutes), meaning that 293 participants on average won 12 minutes of sleep every day over the work days. On free 294 days, participants then went to bed and woke up at similar times to those before COVID29519 , and even slept 10 minutes less than before lockdown, likely due to the prolonged 296 sleeping times during the work week.

297 This shift of sleep to later wake-up-times on workdays confirms our hypothesis and is 298 reflected in the reduction of the social jetlag, which reduced for all participants with an 299 average of 23 minutes. Similar effects are reported by Blume et $\mathrm{al}^{6}$ who show a median 300 social jetlag decrease of 13 minutes. This suggests that without the workweek constraint, 301 sleep during workdays shifts towards participants' more natural rhythm, with later bedtimes 302 and especially awakening times, thereby resembling sleep patterns during free days. The 303 loss of sleep on free days was unexpected, but given the data, it is most likely related to 304 the decrease of sleep debt during the workweek in lockdown. Alternatively, one could 305 speculate that worrying about COVID-19 could have a negative impact on falling asleep 306 and staying asleep on free days, as worry and rumination are known to increase sleep 307 disturbances ${ }^{23,24}$.

308

\section{Cultural effects}

310 The cultural differences we see for total-sleep-time and time-in-bed indicate that, on

311 workdays, participants from Cuba and Ukraine sleep more than the other countries, 312 independently of the lockdown. The country effects for bedtimes and wake-up-times point 313 out Greece and Ukraine as those who go to bed and wake up the latest on workdays, 314 irrespective of the lockdown. These results confirm our hypothesis that sleeping habits 315 differ from country to country.

316 Two aspects may explain these differences: sociocultural factors and the geographical 317 location, which determines the amount of daily sunlight at time of data sampling. During 
318 spring and summer (the time when the data was collected), in Ukraine, Germany and 319 Austria the sun rises earlier and sets later than in Greece and Cuba, while Brazil is in 320 between $^{25}$. This gives the former countries more hours of daylight than the latter. However, 321 in our analyses, Ukraine and Greece had the latest bedtimes and wake-up-times from all 322 the countries analysed, even though they got very different amounts of sunlight during the 323 day. This leaves sociocultural factors (i.e. customs, lifestyle) as the main influence on the 324 intercultural sleep differences. Interestingly, the results indicate that COVID-19 affected 325 sleep in all countries in the same way with no specific cross-cultural effects.

326

\section{Job effects}

328 Participants with system relevant jobs woke up, on average, 37 minutes earlier and slept 32922 minutes less on workdays than participants with system irrelevant jobs, while no 330 differences were found on free days. This also results in a bigger social jetlag for 331 individuals with system relevant jobs than for those with system irrelevant jobs irrespective 332 of the lockdown.

333 Data show a trend that social jetlag decreased during lockdown more strongly for 334 participants with system irrelevant jobs (on average 26 minutes) than for those with system 335 relevant jobs (on average 14 minutes). These results support our hypothesis that 336 participants with system relevant jobs would have earlier wake-up-times and less overall 337 sleep, whereas participants with system irrelevant jobs managed to catch up on sleep with 338 later wake-up-times on workdays (cf. Figure 1B). In this respect, the current study is an 339 important extension of existing literature ${ }^{6}$, endorsing the theory that system relevant and 340 system irrelevant jobs have very different situations and environmental constraints when it 341 comes to sleeping times.

342

\section{Age effects}


344 We refrain from formulating hypotheses regarding the influence of age, but one age effect

345 attracted our attention: there was a negative correlation between age and social jetlag

346 before, but not during lockdown (cf. Supp. Figure 2). That is, under normal social

347 circumstances, young people have a higher social jetlag than older people, but during

348 lockdown, this effect disappears. This suggests that the permission to work from home

349 office and the ban on social events during the COVID-19 lockdown reduced this work/free

350 difference for young people more than it did for the older ones. As an implication of these

351 results, young people may feel the pressure of the lockdown more strongly than older

352 people, which might make them less inclined to comply with the distancing measures,

353 especially since they are at a lower risk for serious complications of the disease. On the

354 other hand, a reduction in social jetlag may indicate that younger people returned, during

355 lockdown, to their inherent activity/rest rhythm, which may also have positive effects on

356 their overall health during lockdown.

357

\section{Subjective sleep quality}

359 Almost two thirds of our participants reported no change in sleep quality during lockdown, 360 which contradicts our hypothesis and is also in disagreement with observed (yet mild)

361 overall decrease in sleep quality in the study of Blume and colleagues ${ }^{6}$. However, in our

362 study, subjective sleep quality is highly correlated with the individual subjective concern

363 regarding COVID-19, and gets worse the more concern is reported (cf. Figure 3). The

364 reduction in subjective sleep quality for this segment of the population has major

365 implications, since low sleep quality is associated with higher risk for depression, suicide ${ }^{25}$,

366 and even immune system dysfunctions ${ }^{26}$, and therefore can aggravate the risk of serious

367 long-term costs on health and well-being. 


\section{Conclusion}

370 Altogether, the results indicate (i) worse perceived sleep quality in participants worrying 371 about COVID-19, (ii) a shift of bedtimes to later hours on workdays, and (iii) a marked 372 reduction of the social jetlag during the COVID-19 lockdown due to a normalization or 373 harmonization of sleeping times between workdays and free days.

374 Although the study sample is not huge, we would like to point to the fact that we actually 375 find very coherent effects across 5 different countries/regions when it comes to changes 376 due to the COVID-19 lockdown measures.

377 When it comes to cross-cultural sleep habits, we see that these vary substantially between 378 culture, and we do find the expected variation ${ }^{27,28}$ in bedtimes and wake-up times with later 379 times for the Greek and Ukrainian samples as compared to Austrian, Brazilian and Cuban 380 samples. Upcoming studies such as the "International COVID-19 Sleep Study (ICOSS)", 381 initiated by Prof. Markku Partinen from Helsinki, will be covering 15 countries from Europe, 382 Asia and North America, and will substantially contribute to our current knowledge on 383 intercultural differences in sleep during COVID-1929. We are looking forward to seeing how 384 such results will extend recent findings. 


\section{Ethics approval and informed consent}

387 The study received approval from the Ethics Committee of the Paris Lodron University of 388 Salzburg, Austria. Informed consent was obtained from each participant. The study was 389 conducted according to the guidelines of the Declaration of Helsinki.

390 
391 References

392 1. Team TNCPERE. The Epidemiological Characteristics of an Outbreak of 2019

393 Novel Coronavirus Diseases (COVID-19) - China. CCDC Weekly. 2020;2(x).

394 2. Organisation WH. WHO Timeline on COVID-19. https://www.who.int/news-

395 room/detail/27-04-2020-who-timeline---COVID-19. Published 2020. Accessed

$396 \quad 21.07 .2020$.

397 3. Lau H, Khosrawipour V, Kocbach $\mathrm{P}$, et al. The positive impact of lockdown in

398 Wuhan on containing the COVID-19 outbreak in China. J Travel Med.

$399 \quad 2020 ; 27(3)$.

400 4. Flaxman S, Mishra S, Gandy A, et al. Estimating the effects of non-

$401 \quad$ pharmaceutical interventions on COVID-19 in Europe. Nature.

$402 \quad 2020 ; 584(7820): 257-261$.

403 5. Morin CM, Carrier J, Bastien C, Godbout R, Canadian S, Circadian N. Sleep

404 and circadian rhythm in response to the COVID-19 pandemic. Can J Public

$405 \quad$ Health. 2020;111(5):654-657.

406 6. Blume C, Schmidt MH, Cajochen C. Effects of the COVID-19 lockdown on

407 human sleep and rest-activity rhythms. Curr Biol. 2020;30(14):R795-R797.

408 7. Beck F, Léger D, Fressard L, Peretti-Watel P, Verger P, Coconel G. Covid-19

409 health crisis and lockdown associated with high level of sleep complaints and

410 hypnotic uptake at the population level. Journal of sleep research.

$411 \quad$ 2020:e13119-e13119.

412 8. Broche-Pérez $\mathrm{Y}$, Fernández-Fleites Z, Jiménez-Puig E, Fernández-Castillo $\mathrm{E}$, 413 Rodríguez-Martin BC. Gender and Fear of COVID-19 in a Cuban Population $414 \quad$ Sample. Int J Ment Health Addict. 2020:1-9. 
415 9. Cellini N, Canale N, Mioni G, Costa S. Changes in sleep pattern, sense of time and digital media use during COVID-19 lockdown in Italy. Journal of sleep research. 2020:e13074-e13074.

10. Gualano MR, Lo Moro G, Voglino G, Bert F, Siliquini R. Effects of Covid-19 Lockdown on Mental Health and Sleep Disturbances in Italy. Int J Environ Res Public Health. 2020;17(13):4779.

11. Kaparounaki CK, Patsali ME, Mousa D-PV, Papadopoulou EVK, Papadopoulou KKK, Fountoulakis KN. University students' mental health amidst the COVID-19 quarantine in Greece. Psychiatry research. 2020;290:113111-113111.

12. Kokou-Kpolou CK, Megalakaki O, Laimou D, Kousouri M. Insomnia during COVID-19 pandemic and lockdown: Prevalence, severity, and associated risk factors in French population. Psychiatry research. 2020;290:113128-113128.

13. Leone MJ, Sigman M, Golombek DA. Effects of lockdown on human sleep and chronotype during the COVID-19 pandemic. Curr Biol. 2020;30(16):R930-R931.

14. Llibre-Guerra JJ, Jiménez-Velázquez IZ, Llibre-Rodriguez JJ, Acosta D. The impact of COVID-19 on mental health in the Hispanic Caribbean region. Int Psychogeriatr. 2020:1-4.

15. Marelli S, Castelnuovo A, Somma A, et al. Impact of COVID-19 lockdown on sleep quality in university students and administration staff. J Neurol. 2020:1-8.

16. Voitsidis P, Gliatas I, Bairachtari V, et al. Insomnia during the COVID-19 pandemic in a Greek population. Psychiatry research. 2020;289:113076113076.

17. Huang Y, Zhao N. Generalized anxiety disorder, depressive symptoms and sleep quality during COVID-19 outbreak in China: a web-based cross-sectional survey. Psychiatry Res. 2020;288:112954.

440 18. Xiao H, Zhang Y, Kong D, Li S, Yang N. The Effects of Social Support on Sleep Quality of Medical Staff Treating Patients with Coronavirus Disease 2019 
(COVID-19) in January and February 2020 in China. Med Sci Monit. 2020;26:e923549.

19. Gao C, Scullin MK. Sleep health early in the coronavirus disease 2019 (COVID19) outbreak in the United States: integrating longitudinal, cross-sectional, and retrospective recall data. Sleep Med. 2020;73:1-10.

20. MATLAB. 9.7.0.1190202 (R2019b). Natick, Massachusetts: The MathWorks Inc.; 2019.

21. Noguchi K, Gel YR, Brunner E, Konietschke F. nparLD: An R Software Package for the Nonparametric Analysis of Longitudinal Data in Factorial Experiments. 2012. 2012;50(12):23.

22. rstatix: Pipe-Friendly Framework for Basic Statistical Tests. R package version 0.6.0 [computer program]. 2020-06-18.

23. McGowan SK, Behar E, Luhmann M. Examining the Relationship Between Worry and Sleep: A Daily Process Approach. Behav Ther. 2016;47(4):460-473.

24. Palagini L, Mauri M, Banfi T, et al. Daytime rumination as a feature of Insomnia Disorder: sleep related cognition is not merely a problem of the night. Arch Ital Biol. 2015;153(2-3):239-247.

25. Thorsen S. Time and Date AS 1995-2020. https://www.timeanddate.com/. Accessed 21.09.2020, 2020.

26. Besedovsky L, Lange T, Haack M. The Sleep-Immune Crosstalk in Health and Disease. Physiol Rev. 2019;99(3):1325-1380.

27. Bliwise DL. Invited Commentary: Cross-Cultural Influences on SleepBroadening the Environmental Landscape. American Journal of Epidemiology. 2008;168(12):1365-1366.

28. Randler C, Prokop P, Sahu S, Haldar P. Cross-cultural comparison of seven morningness and sleep-wake measures from Germany, India and Slovakia. Int J Psychol. 2015;50(4):279-287. 
469 29. Markku Partinen BB, Brigitte Holzinger, Frances Chung, Thomas Penzel, Colin

A. Espie, Charles M. Morin. ICOSS- International Covid Sleep Study. Sleep and Circadian Problems during the COVID-19 Pandemic, An International 2020; under submission.

474

475 


\section{Figure Legends}

477 Figure 1: (A) Differences in total-sleep-times during minus before COVID-19 lockdown, 478 for system relevant and system irrelevant jobs. On workdays (red) participants with 479 system irrelevant jobs sleep more during lockdown than before, but participants with 480 system relevant jobs do not. On free days (green), all participants sleep less during the 481 lockdown than before. (B) Differences in bedtimes and wake up times during minus 482 before COVID-19 lockdown, for system relevant and system irrelevant jobs. On 483 workdays (red), both job groups go to bed and wake up later during lockdown than 484 before. On free days (green), participants from both job groups go to bed a little later 485 during than before the lockdown, but wake up at almost the same time as before the 486 lockdown. Negative values describe a loss of sleep during lockdown; positive values 487 describe a gain in sleep during lockdown.

488 Figure 2: Social Jetlag in hours (difference of sleep midpoint of working minus sleep 489 midpoint of free days) for system relevant $(n=108)$ and system irrelevant $(n=262)$ jobs 490 before and during COVID-19. Note that during COVID-19 there is reduced social jetlag 491 for both groups. Participants with system relevant jobs reported higher social jetlag than 492 participants with system irrelevant jobs, independent of the COVID-19 situation. ( ${ }^{*} \mathrm{p}<$ $\left.493.05,{ }^{* *} p<.001\right)$.

494 Figure 3: Effects of worry about the COVID-19 pandemic on subjective sleep quality 495 visualised as $\mathrm{X}^{2}$ residuals. Note that people who do not (or barely) worry are less likely 496 (than expected) to sleep worse (in red), whereas the participants who worry a lot about 497 the pandemic are more likely to sleep worse (in blue). 


\begin{tabular}{|c|c|c|c|c|c|c|c|c|c|}
\hline \multicolumn{10}{|c|}{ A. Sleep before and during lockdown on workdays } \\
\hline & & \multicolumn{2}{|c|}{ Total Sleep } & \multicolumn{2}{|c|}{ Time in Bed } & \multicolumn{2}{|c|}{ Going to Bed } & \multicolumn{2}{|c|}{ Wake Up } \\
\hline & & Mean & SD & Mean & SD & Mean & SD & Mean & SD \\
\hline \multicolumn{2}{|c|}{ Country } & & & & & & & & \\
\hline \multirow[t]{2}{*}{ Austria * } & Before & 07:03 & $00: 59$ & 07:32 & $01: 08$ & 23:02 & $00: 55$ & $06: 30$ & $00: 55$ \\
\hline & During & 07:05 & 01:04 & 07:40 & $01: 08$ & 23:29 & $00: 52$ & 07:04 & 01:09 \\
\hline \multirow[t]{2}{*}{ Greece } & Before & 07:01 & 01:07 & 07:06 & 01:01 & 24:01 & 01:03 & 07:01 & $01: 12$ \\
\hline & During & 07:20 & 01:08 & 07:25 & 01:11 & $24: 32$ & 01:28 & 07:53 & $01: 41$ \\
\hline \multirow[t]{2}{*}{ Ukraine } & Before & 07:33 & 01:08 & 07:50 & $00: 58$ & $23: 35$ & $01: 10$ & $07: 23$ & $01: 20$ \\
\hline & During & 07:52 & $01: 15$ & 08:06 & $01: 17$ & $23: 51$ & 01:29 & $07: 54$ & $01: 33$ \\
\hline \multirow[t]{2}{*}{ Cuba } & Before & 07:33 & 01:03 & $07: 36$ & $00: 56$ & $22: 56$ & $00: 50$ & $06: 30$ & $00: 48$ \\
\hline & During & 07:34 & 01:04 & $07: 43$ & 01:02 & $23: 15$ & $00: 59$ & $06: 54$ & 01:04 \\
\hline \multirow[t]{2}{*}{ Brazil } & Before & 07:08 & 01:09 & 07:21 & $00: 57$ & $23: 17$ & 01:12 & $06: 35$ & $01: 10$ \\
\hline & During & $07: 21$ & $01: 18$ & 07:33 & $01: 17$ & $23: 43$ & $01: 41$ & $07: 15$ & $01: 45$ \\
\hline \multicolumn{2}{|c|}{ Job } & & & & & & & & \\
\hline \multirow[t]{2}{*}{$\begin{array}{l}\text { System } \\
\text { Relevant }\end{array}$} & Before & 07:09 & 01:02 & $07: 16$ & $00: 58$ & 23:09 & $00: 56$ & $06: 27$ & $00: 52$ \\
\hline & During & 07:10 & 01:07 & 07:20 & 01:05 & 23:32 & 01:10 & $06: 53$ & $01: 18$ \\
\hline
\end{tabular}




\begin{tabular}{|l|l|l|l|l|l|l|l|l|l|}
\hline $\begin{array}{l}\text { System } \\
\text { Irrelevant }\end{array}$ & Before & $07: 23$ & $01: 08$ & $07: 36$ & $01: 01$ & $23: 26$ & $01: 09$ & $06: 57$ & $01: 13$ \\
\hline & During & $07: 38$ & $01: 11$ & $07: 52$ & $01: 13$ & $23: 49$ & $01: 28$ & $07: 36$ & $01: 32$ \\
\hline
\end{tabular}

\begin{tabular}{|c|c|c|c|c|c|c|c|c|c|}
\hline \multicolumn{10}{|c|}{ B. Sleep before and during lockdown on free days } \\
\hline & & \multicolumn{2}{|c|}{ Total Sleep } & \multicolumn{2}{|c|}{ Time in Bed } & \multicolumn{2}{|c|}{ Going to Bed } & \multicolumn{2}{|c|}{ Wake Up } \\
\hline & & Mean & SD & Mean & SD & Mean & SD & Mean & SD \\
\hline \multicolumn{10}{|c|}{ Country } \\
\hline \multirow[t]{2}{*}{ Austria * } & Before & 08:21 & 00:55 & 08:41 & $00: 57$ & 23:55 & $01: 11$ & 08:31 & 01:17 \\
\hline & During & 07:58 & 01:02 & 08:29 & 01:01 & 24:00 & 01:08 & 08:19 & 01:18 \\
\hline \multirow[t]{2}{*}{ Greece } & Before & 08:07 & 01:02 & 08:07 & $00: 58$ & 24:59 & $01: 16$ & 09:04 & $01: 38$ \\
\hline & During & 07:59 & 01:18 & 08:01 & $01: 15$ & $25: 12$ & 01:29 & 09:12 & 01:42 \\
\hline \multirow[t]{2}{*}{ Ukraine } & Before & 08:27 & 01:18 & 08:38 & 01:05 & 24:03 & 01:08 & 08:42 & $01: 34$ \\
\hline & During & 08:20 & $01: 20$ & 08:30 & 01:12 & $24: 15$ & 01:25 & 08:46 & $01: 42$ \\
\hline \multirow[t]{2}{*}{ Cuba } & Before & 08:38 & 01:00 & $08: 41$ & $00: 59$ & $23: 58$ & $01: 14$ & 08:37 & 01:08 \\
\hline & During & 08:29 & 01:02 & 08:34 & 01:01 & 24:03 & 01:05 & 08:32 & 01:09 \\
\hline \multirow[t]{2}{*}{ Brazil } & Before & $08: 15$ & 01:12 & 08:28 & $00: 55$ & 24:02 & $01: 17$ & 08:22 & $01: 26$ \\
\hline & During & 08:04 & $01: 21$ & 08:14 & 01:19 & $24: 22$ & $00: 15$ & 08:31 & 01:55 \\
\hline Job & & & & & & & & & \\
\hline
\end{tabular}




\begin{tabular}{|l|l|l|l|l|l|l|l|l|l|}
\hline \multirow{2}{*}{$\begin{array}{l}\text { System } \\
\text { Relevant }\end{array}$} & Before & $08: 27$ & $00: 58$ & $08: 28$ & $01: 03$ & $23: 59$ & $01: 10$ & $08: 30$ & $01: 09$ \\
\cline { 2 - 9 } & During & $08: 10$ & $01: 09$ & $08: 20$ & $01: 07$ & $24: 16$ & $01: 22$ & $08: 34$ & $01: 25$ \\
\hline \multirow{2}{*}{$\begin{array}{l}\text { System } \\
\text { Irrelevant }\end{array}$} & Before & $08: 22$ & $01: 10$ & $08: 33$ & $00: 59$ & $24: 15$ & $01: 19$ & $08: 43$ & $01: 47$ \\
\cline { 2 - 9 } & During & $08: 15$ & $01: 15$ & $08: 24$ & $01: 12$ & $24: 23$ & $01: 30$ & $08: 43$ & $01: 51$ \\
\hline
\end{tabular}

500 Table 1. Sleep values before and during lockdown, on workdays (A) and on free days

501 (B). All values are in $\mathrm{HH}: \mathrm{MM}$ format and represent the average from all participants in

502 that group (job or country). *Includes values from Austria (55 participants) and

503 Germany (16 participants). 


\section{Acknowledgements}

505 We would like to thank our cooperation partners:

506 Ukraine:

507 - Principal investigator: Anton Kurapov, Department of Experimental and Applied

508 Psychology, Faculty of Psychology, Taras Shevchenko National University of

$509 \quad$ Kiev, Ukraine

510 Cuba:

511 - Principal investigator: Carlos Alberto Beltran Leon; Institute of Neurology and

512 Neurosurgery, Department of Clinical Neurophysiology, Havana, Cuba

$513 \quad-\quad$ We are also grateful for the help of Yeney Fundora Perez, Daniel Ferral

514 Arevalo, Maria Bianco Rojas, David Almeida Bianco, Aldel Almeida Cedeno,

515 Ervin Fernanon Lopez, Ivan Vazquez Figueredo and Leticia Arevalo Nueva in

516 data acquisition.

517 Greece:

518 - We would like to thank Anastasia Chandolia and Vasiliki Chandolia for their 519 help in data collection.

520

521

522 Funding

523 Cristina Florea, Pavlos Topalidis and Monika Angerer: supported by the doctoral school

524 DK Imaging the Mind, funded by the Austria Science Fund (FWF, W-1223 G17).

525 Monika Angerer: also supported by the Austria Science Fund (FWF, Y-777). 